\title{
EXPERIÊNCIAS DE UTILIZAÇÃO DE ARTEFATOS HISTÓRICOS EM ATIVIDADES DE ENSINO
}

\section{EXPERIENCES FOR THE USE OF HISTORICAL ARTIFACTS IN TEACHING ACTIVITIES}

\author{
Rosalba Lopes de Oliveira ${ }^{1}$ \\ Instituto Kennedy/Natal/RN
}

\begin{abstract}
RESUMO
Este artigo tem como objetivo apresentar experiências de uso de artefatos históricos em atividades de ensino como possibilidade de abordagem de conteúdos matemáticos, em sala de aula da Educação Básica. Trata-se de pesquisa bibliográfica realizada em livros, dissertação e outros textos que enfocaram a utilização da História da Matemática e Artefatos Históricos como recursos motivadores para desenvolver de temáticas relacionadas ao conhecimento matemático. Como respaldo teórico, foram utilizadas as ideias de D'Ambrosio (1996), Funari (2003), Lorenzato (2006), Fossa (2006), Duarte (1989), Gutierre (2003) e Mendes (2005), que permitiram evidenciar o conceito de artefatos e os aspectos significativos da utilização de artefatos históricos no ensino da matemática. As experiências ressaltadas no texto, permitiram constatar que o uso de artefatos no ensino, possibilitaram a participação ativa do aluno na resolução das atividades propostas, a construção e manipulação de materiais concretos, além do desenvolvimento de habilidades de realização de pesquisas, leituras e registros que traduziram a compreensão do conteúdo estudado.
\end{abstract}

Palavras-chave: Artefatos Históricos. Experiência docente. Ensino de Matemática.

\section{ABSTRACT}

This article aims to present experiences of use of historical artifacts in teaching activities as a possibility to approach mathematical contents in the classroom of Basic Education. It is a bibliographical research carried out in books, dissertation and other texts that focused on the use of History of Mathematics and Historical Artifacts as motivating resources to develop topics related to mathematical knowledge. As a theoretical support, the ideas of D'Ambrosio (1996), Funari (2003), Lorenzato (2006), Fossa (2006), Duarte (1989), Gutierre (2003) and Mendes (2005) were used. Concept of artifacts and the significant aspects of the use of historical artifacts in the teaching of mathematics. The experiences highlighted in the text allowed us to verify that the use of artifacts in teaching enabled the active participation of the student in solving the proposed activities, the construction and manipulation of concrete materials, as well as the development of research skills, readings and records that Translated the understanding of the studied content.

\footnotetext{
${ }^{1}$ E-mail: 1rosalba@supercabo.com.br.
} 
Keywords: Historical Artifacts. Teaching experience. Mathematics Teaching.

\section{Introdução}

Desde a antiguidade, o homem busca meios para resolver seus problemas e satisfazer suas necessidades básicas. Nesta tentativa, planeja suas ações, constrói instrumentos que the auxiliam nesta empreitada, cria formas de se comunicar desenvolvendo a linguagem e, com esse aprimoramento, elabora meios mais eficazes para transmitir os conhecimentos até então apreendidos. Ao pensar como interferir no meio em que vive, como registrar seus saberes e suas transações comerciais, como compreender os processos de organização da sociedade, o homem criou instrumentos e artefatos que permitiram contar, hoje, a sua história.

Na dinâmica da construção do conhecimento matemático, provavelmente, foram necessários a exploração ou reconstrução de alguns artefatos que permitiram uma nova forma de conhecer e explicar a construção histórica desse conhecimento. Pensando assim, no nosso trabalho de pesquisa denominamos de "artefatos", todo e qualquer objetos que estejam ligados direta ou indiretamente à história das civilizações antigas.

No estudo das civilizações antigas, nos deparamos com objetos que representam valores simbólicos criados pelo homem num determinado espaço e tempo da história, e que, portanto, são dotados de significados dentro de um contexto cultural e social. Esses objetos são denominados de artefatos. Para entender o papel dos artefatos no trabalho do professor fomos buscar no livro Arqueologia de Pedro Paulo Funari (2003), que esclarece que a possibilidade de interpretação e compreensão de um objeto de estudo se dar,

[...] pelo fato dos artefatos serem produto do trabalho humano, e, portanto, apresentarem necessariamente duas facetas: terem uma função primária (uma utilidade prática) e funções secundárias (simbólicas). [...] Artefatos, por outro lado, não é apenas um indicador de relações sociais, mas, enquanto parte da cultura material, atua como direcionador e mediador das atividades humanas. (FUNARI, 2003, p.33)

Com esse entendimento, podemos inferir que os artefatos buscam determinar comportamentos específicos das pessoas no cerne de uma sociedade, como também a vida cotidiana das civilizações e a relação de poder e prestígio exercido pelos os indivíduos no seu contexto social. Dessa forma, D’Ambrósio (1996, p. 140), conceitua 
artefatos como "manifestações concretas da criatividade humana, transmissíveis de indivíduo para indivíduo através de contato direto ou remoto. " $\mathrm{Na}$ Arqueologia os artefatos são objetos ou parte de um objeto feito pelo homem que fornecem indicações sobre a época a que pertenceu, que permitem extrair informações sobre as sociedades e realizar inferências sobre estes, de modo a ampliar o conhecimento do aluno.

No exercício do manuseio do artefato o aluno imerge na cultura das antigas civilizações produzindo conhecimentos sobre aspectos até então desconhecido, trazendo também, a possibilidades de conhecimentos das práticas culturais presentes no cotidiano dessas civilizações, além de interrogações sobre a construção desses conhecimentos. $\mathrm{O}$ agir sobre os objetos provoca uma nova forma de aprender diferente daquela em que o aluno ouve falar sobre determinado artefato antigo.

Por meio do manuseio de objetos antigos o professor mergulha na ação de descobrir e prosseguir numa viagem ao passado, na tentativa de entender o contexto cultural que os geraram, constituindo uma importante fonte para criar novas formas de abordar a evolução do conhecimento matemático. Para Lorenzato (2006) é conveniente que o professor perceba que:

Ao longo dos milênios, o ritmo de construção da matemática não foi sempre o mesmo. É interessante, principalmente para nós professores, observar que aquilo que os matemáticos demoraram em descobrir, inventar ou aceitar, são os mesmos pontos em que os nossos alunos apresentam dificuldades de aprendizagem. Essa coincidência entre os obstáculos cognitivos históricos e os pontos de maior dificuldade de aprendizagem em sala de aula é reconhecida por muitos pensadores, matemáticos ou educadores de renome, (...) Constitui-se em uma importante questão didática para todos os responsáveis pelo ensino da matemática. (LORENZATO, 2006, p.107)

Ao professor compete despertar, no aluno, a vontade de aprender e, no nosso caso, aprender matemática, que poderá ser feito se o professor pensar na matemática como um objeto de estudo em movimento, interligado com os diferentes saberes e que sua aprendizagem ocorre na ação do aluno com esse objeto, por meio de experimentação, de descoberta, de atividades lúdicas e outras. Nesse sentido, Lorenzato (2006) esclarece que:

[...] a experimentação pode ser concebida como ação sobre objetos (manipulação), com valorização da observação, comparação, montagem, decomposição, (separação), distribuição. Mas, a importância da experimentação reside no poder que ela tem de conseguir provocar 
raciocínio, reflexão, construção de conhecimento. (LORENZATO, 2006, p.72)

Compreendemos que o ensino de matemática tem negligenciado sobre este aspecto de fazer o aluno pensar, talvez porque o ato de ensinar, para o professor, ainda está baseado na transmissão do conhecimento para um ser passivo que recebe esse saber sem contestação. Quando é dado ao professor o espaço para descobrir regularidades, experimentar caminhos, pesquisar, inferir, refletir sobre suas observações, estamos oportunizando momentos de reconstrução do conhecimento e de elevação da sua autoestima, uma vez que se sente capaz de realizar estudos relevantes para sua atuação docente e o seu crescimento enquanto cidadão. Para tanto, é preciso mudanças na forma do professor abordar os conteúdos matemáticos na perspectiva de integração de temas e de modificação da autoestima do aluno.

$\mathrm{O}$ texto deste artigo foi estruturado em três seções. Na primeira, introdução, destacamos as ideias sobre o conceito de artefatos e a sua importância na produção do conhecimento ao longo da histórica das civilizações. Destacamos na segunda seção, experiências de utilização de artefatos históricos em atividades de ensino, como forma de incentivar o professor para sua utilização como recursos didáticos em sala de aula de Matemática. Enfatizamos na terceira seção algumas considerações sobre a pesquisa realizada.

\section{Experiências de utilização de artefatos históricos no ensino da matemática}

Várias são as pesquisas que apresentam a utilização de artefatos históricos em atividades de ensino, na sala de aula de Matemática da Educação Básica. Neste texto destacamos as atividades desenvolvidas por Duarte (1989), Fossa (2006), Gutierre (2003) e Mendes (2005), como exemplos de uso de artefatos históricos, em contextos escolares, que possibilitaram a apropriação, por parte dos alunos, de conhecimentos matemáticos construídos ao longo da história, além de outros conhecimentos referentes às diferentes áreas do saber.

Newton Duarte em seu livro $O$ ensino de matemática na educação de adultos, apresenta uma proposta para abordagem do conteúdo matemática na sala de aula da 
educação de adultos, por meio de uma prática dirigida em que os alunos poderiam reproduzir concisamente a evolução do conhecimento matemático, recriando-o para si.

O tema abordado nas primeiras atividades era a recriação do ábaco e o sistema de numeração decimal. Inicialmente, foi solicitado aos alfabetizando que apresentassem as formas de registro que cada um havia criado em sua vida, conforme as necessidades de seu trabalho. As formas de registros são criadas para representar parte da contagem já efetuada ou o resultado final. E dessa forma, surgiram diferentes formas de registrar as quantidades, variando o material utilizado e o valor atribuído a cada unidade. Essa atividade, como nos diz Duarte:

[...] nada mais é do que a reprodução da criação histórica das formas de registro que antecederam o ábaco. Superar por incorporação esse saber matemático dos educandos seria fazer com que essas formas fossem sendo sistematizadas numa forma única que acabasse levando à recriação do ábaco. (DUARTE, 1989, p.23)

Partido dessa compreensão foi realizado outras atividades que conduziram a discussão da necessidade de ser adotada uma forma de registro comum a todos e que pudesse comunicar a contagem realizada. $\mathrm{O}$ autor enfatiza que "essa discussão coloca a questão histórica da necessidade de sistematização de formas comuns de expressão e de registro e o fato de escrita matemática ser uma linguagem compreendida pelas mais variadas nações" (DUARTE, 1989, p. 25).

Como forma de estabelecer um registro comum para as contagens realizadas nas atividades que utilizavam a base dez, o autor sugeriu um instrumento muito utilizado na matemática: os dedos das mãos. Foram definindo combinações adotadas no momento da contagem, que possibilitou a comunicação.

Depois dessa atividade foi solicitada aos alunos a construção um instrumento que possibilitasse representar qualquer quantidade: o ábaco. $\mathrm{O}$ autor apresentou a história desse instrumento e sugeriu a construção de um ábaco para cada aluno, com materiais presentes no nosso dia-a-dia, com a finalidade de contribuir para a compreensão dos princípios do sistema de numeração. Duarte reforça que:

Não basta apenas saber escrever os números, é preciso que essa escrita seja a exteriorização de um domínio dos princípios e propriedades do sistema decimal de numeração posicional. Esses princípios e propriedades são melhores compreendidos quando se compreende a sua origem. O sistema decimal de numeração posicional teve no ábaco um instrumento decisivo para a sua formação. (DUARTE, 1989, p. 30) 
A busca de superação da limitação de registrar quantidades utilizando apenas os dedos das mãos conduziu os povos antigos a criar outra forma de registrar: a relação um-para-dez, e esta forma levou à criação de um instrumento, o ábaco, que possibilitou superar a necessidade de registrar, com mais facilidade, quantidades maiores.

A utilização do artefato (ábaco) nas atividades propostas pelo autor contribuiu, para o aluno compreender o processo de criação e desenvolvimento do conhecimento matemático, quanto a forma de registro e a compreensão do sistema de numeração decimal, bem como para o entendimento, das necessidades, limites e obstáculos enfrentados pelas civilizações antigas, para aperfeiçoar as formas de registrar as contagens para que fossem compreendidas por todos.

Como segunda experiência de uso de artefatos históricos nas aulas de matemática, apresentamos o que foi proposto por John A. Fossa (2006), em seu texto Recursos pedagógicos para o ensino da matemática a partir das obras de dois matemáticos da Antiguidade. No texto, o autor busca ilustrar formas de usa a história da matemática como recurso pedagógico no ensino da matemática, tomando como fonte duas obras de matemáticos antigos: Teon de Smyrna e Nicomachus de Gerasa, que segundo o autor, são muito semelhantes em termos de conteúdo e objetivos, no entanto, diferentes em estilo e organização. Para ele, Teon tende a ser mais abstrato e sucinto, por outro lado Nicomachus tende a introduzir mais material explicativo e exemplos numéricos.

Com sugestão de atividades o autor contextualiza, inicialmente, onde os dois matemáticos nasceram, apresentando mapas (artefatos) que mostra a localização das referidas cidades, enfatizando também alguns fatos da vida desses matemáticos. Em seguida, procura destacar alguns aspectos do conteúdo matemático explorados nas obras pesquisadas. O autor diz que "os conceitos aritméticos dos autores antigos estão imersos em um pensamento empírico. Para aproveitar ao máximo esse aspecto da matemática antiga, o aluno deveria investigar os referidos conceitos usando materiais manipulativos" (FOSSA, 2006, p. 143).

O uso de materiais manipulativos foi apresentado no texto para abordagem da classificação mais antiga dos números naturais: em pares ou ímpares. Nos exemplos dados pelos matemáticos os números são representados por coleções de objetos como 
sementes, botões e outros materiais manipulativos e definem como sendo números pares "os que podem ser repartidos em dois grupos iguais. Os números ímpares, em contraste, não podem ser representados em dois grupos iguais, [...]" (FOSSA, 2006, p.145-146).

$\mathrm{O}$ autor sugere que os alunos sejam conduzidos a investigar, usando material concreto, uma sequência de números naturais, indicando sua classificação em par ou ímpar. Em seguida, tentar registrar em quadros a ação desenvolvida. Dessa forma, o entendimento do aluno sobre o que é número par e ímpar torna-se mais facilitada. A ideia de utilizar materiais manipulativos tenta contribuir para tornar-se bastante concreta o método que os dois matemáticos utilizaram para definir números pares e ímpares. Para eles, a presença de um resto não nulo, em uma divisão, significa que esse número não pertence a esta classe numérica. De forma semelhante, diz o autor, pode ser abordada a operação divisão, por qualquer número natural.

Outras atividades foram sugeridas pelo autor para abordagem de conteúdos como: potências de dois; números primos; números triangulares; números quadrados; números pentagonais e hexagonais; números retangulares; números piramidais, entre outros. Todos utilizando o material manipulativo. O resultado, segundo Fossa (2006, p. 182), "são atividades empolgantes que proporcionam exercícios de fixação não rotineiros, bem como atividades que promovam o desenvolvimento do pensamento crítico e as habilidades metacognitivas."

Utilizar-se de artefatos históricos que proporcionem temas de estudo interessantes para o aluno, provavelmente, torna-o mais engajado nas atividades propostas, desenvolvendo sua confiança em resolvê-las adquiridos novos conhecimentos.

Uma terceira referência de utilização de artefatos em atividades de ensino foi destacada na dissertação de Liliane dos Santos Gutierre: Inter-relações entre a História da Matemática, a Matemática e sua aprendizagem. Nas atividades propostas na dissertação, a autora apresenta figuras, mapas, textos históricos e outros instrumentos relacionados a diferentes civilizações as quais o estudo fazia referência. Gutierre (2003) esclarece que:

Tendo em vista que estudaríamos pelo menos cinco civilizações, através de cinco "paradas", achamos necessário situar o aluno no espaço, em relação ao Brasil, convidando-o a localizar o Egito no mapa mundi e no mapa que 
focalizava o nordeste da África. Para tanto, retomamos conteúdos, tais como: pontos colaterais e pontos cardeais. (GUTIERRE, 2003, p. 71)

Era sugerido ao aluno identificar qual o período da história as figuras se referiam localizar nos mapas as principais cidades, os rios e outros pontos de relevância para aquele estudo. Estes instrumentos contribuíram para a contextualização da civilização e a integração de conteúdos que a autora abordou em sala de aula da $8^{\mathrm{a}}$ série do Ensino Fundamental, numa escola pública da cidade do Natal.

O estudo em destaque tratava-se da resolução das equações ao longo da história. Para tanto, inicialmente utilizou-se da réplica de um problema do Papiro de Rhind que procurava descobrir o valor de uma quantidade desconhecida (AHA). A partir desses problemas foi apresentado para o aluno o método que os Egípcios usaram para resolvêlo. E assim, Gutierre (2003, p. 77) coloca que "Através da leitura do texto que continha a apostila 2, os alunos adquiriram ou relembravam conhecimentos, tais como: povos sumerianos, escrita cuneiforme, tabletes de barro, equação do $2^{\circ}$ e $3^{\circ}$ graus, entre outros. " Dando prosseguimento as atividades propostas pela autora, foram estudados como eram resolvidas as equações pelas outras civilizações antigas.

Sempre ao iniciar o estudo do método de resolução de equação por cada civilização, a autora buscava elementos que os representavam, tais como: textos da história da matemática, mapa mundi, tabletes mesopotâmicos, réplicas do Papiro de Rhind, materiais manipulativos, entre outros, como forma de contribuir com os alunos na ampliação do seu conhecimento, motivar o estudo do conteúdo abordado, discussão das diferentes formas de resolução das equações do $1^{\circ}, 2^{\circ}$ e $3^{\circ}$ graus, ao longo da história e dar significado a fórmula utilizada, atualmente, para resolver equação do $2^{\circ}$ grau. Possibilitou também a ampliação do conhecimento dos alunos, além do conhecimento matemático o conhecimento de outras áreas do conhecimento.

Outra indicação de uso de artefatos da história em atividade de ensino está em destaque no livro História da Matemática em atividades didáticas, no qual Mendes (2005), apresenta alguns artefatos que foram utilizados para abordar conteúdos relacionados a noção de proporcionalidade e semelhança de triângulos retângulos, como também as noções de trigonometria. Entre as atividades propostas contemplava a construção e exploração de uma réplica do relógio de sol. Segundo o autor: 
Os aspectos históricos apresentados nesta atividade têm um caráter provocador para aos estudantes, tendo em vista lançar-lhes vários desafios, dentre os quais podemos citar: uma pesquisa mais detalhada acerca dos relógios de sol; um estudo acerca das modificações realizadas na técnica de medir o tempo até chegar aos relógios atuais; um estudo sobre a trigonometria relacionada aos relógios de sol; uma investigação acerca da exploração dessas ideias por diferentes grupos culturais, etc. (MENDES, 2005, p. 69)

Todas essas ações fazem com que o aluno perceba o processo histórico da construção da ciência, refletindo sobre as contribuições oferecidas por cada grupo social em diferentes momentos históricos e, consequentemente, a ampliação da compreensão sobre o tema estudado.

Outra atividade ressaltada no livro foi a construção e exploração do trigonômetro. Mendes (2005, p. 76) esclarece que "Esse instrumento de medição das razões trigonométricas tem uma relação intima com o astrolábio, cuja origem atribui-se aos inventos astronômicos de Hiparco". Por meio da experiência de construção e utilização do trigonômetro os alunos poderão compreender o significado das razões trigonométricas, bem como experienciar situações mais próximas das vivenciadas pelos matemáticos da antiguidade.

\section{Considerações sobre o trabalho}

No exercício do manuseio o aluno será capaz de lançar hipóteses, inferir sobre determinados aspectos, observar detalhes até então não observados e mergulhar na cultura da civilização que o representa. Dessa forma, temos condições de pensar num trabalho interdisciplinar que conduzam a temos uma atitude de ver as coisas integradas, e ao mesmo tempo observar as suas especificidades.

Estes dois elementos (artefatos e manuseio) foram incorporados nas atividades de ensino destacadas nestas experiências expostas no texto. Nestas atividades foram enfatizadas a participação ativa do aluno na construção do seu conhecimento matemático, refletindo sobre a ação que está sendo realizada, bem como a ampliação do conhecimento do professor na busca de alternativas metodológicas para explorar os conteúdos matemáticos em sala de aula. Dessa forma, consideramos que o uso de artefatos históricos e o seu manuseio, provavelmente, promoverá reflexões e estímulos para que os professores possam criar seus próprios artefatos, como também oferecer pistas de articulação com outras áreas do conhecimento. 
Nos exemplos apresentados os artefatos possibilitaram a participação ativa do aluno na resolução das atividades, a construção e manipulação de materiais concretos, além do desenvolvimento de habilidades de realização de pesquisas, leituras e registros que traduziam a compreensão do conteúdo estudado.

\section{Referências}

D’AMBRÓSIO, Ubiratan. Educação Matemática: da teoria à prática. São Paulo: Papirus, 1996.

DUARTE, Newton. $O$ ensino de matemática na educação de adultos. 3.ed. São Paulo: Cortez, 1989. (Coleção educação contemporânea).

FOSSA, John A. Recursos pedagógicos para o ensino da matemática a partir das obras de dois matemáticos da Antiguidade. In: MENDES, I. A.; FOSSA, J. A.; VALDÉS, J. E. N. A história como um agente de cognição na Educação Matemática. Porto Alegre: Sulina, 2006.

FUNARI, Pedro Paulo. Arqueologia. São Paulo: Contexto, 2003. 124p.

GUTIERRE, Liliane dos Santos. Inter-relações entre a História da Matemática, a Matemática e sua Aprendizagem. 2003. Dissertação (Mestrado). Universidade Federal do Rio Grande do Norte. Programa de Pós-Graduação em Educação, Natal, RN, 2003.

LORENZATO, Sergio. Para aprender matemática. Campinas, SP: Autores Associados, 2006. (Coleção Formação de professores). 139p.

MENDES, Iran Abreu. Atividades históricas para o ensino de trigonometria. In: BRITO, Arlete de Jesus et al. História da Matemática em atividades didáticas. Natal: EDUFRN - Editora da UFRN, 2005. 